\title{
The rebound effect through industrial ecology's eyes: a review of LCA-based studies
}

\author{
David Font Vivanco $\cdot$ Ester van der Voet
}

Received: 28 February 2014 / Accepted: 8 September 2014 / Published online: 16 September 2014

(C) Springer-Verlag Berlin Heidelberg 2014

\begin{abstract}
Purpose Industrial ecology academics have embraced with great interest the rebound effect principle operationalised within energy economics. By pursuing more comprehensive assessments, they applied tools such as life cycle assessment (LCA) to appraise the environmental consequences of the rebound effect. As a result, the mainstream rebound mechanism was broadened and a diversity of (sometimes inconsistent) definitions and approaches unveiled. To depict the state of play, a comprehensive literature review is needed.

Methods A literature review has been carried out by targeting scientific documents relevant for the integration of the rebound effect into LCA-based studies. The search was conducted using two approaches: (1) via online catalogues using a defined search criterion and (2) via cross-citation analysis from the documents identified through the first approach.

Results and discussion By analysing a total of 42 works yielded during our review, it was possible to bring together the various advantages of the life cycle perspective, as well as to identify the main inconsistencies and uninformed claims present in literature. Concretely, three main advantages have been identified and are discussed: (1) the representation of the rebound effect as a multi-dimensional, life cycle estimate, (2) the improvement of the technology explicitness and (3) the broadening of the consumption and production factors leading to the rebound effect. Also, inconsistencies on the definition and classification of the rebound effect have been found among studies.

Conclusions The review contributes a number of valuable insights to understand how the rebound effect has been treated
\end{abstract}

Responsible editor: Martin Baitz

D. Font Vivanco $(\bowtie) \cdot$ E. van der Voet

Institute of Environmental Sciences (CML), Leiden University, 2300

RA Leiden, Netherlands

e-mail: font@cml.leidenuniv.nl within the industrial ecology and LCA fields. For instance, the conceptual and methodological refinements introduced by these fields represent a step forward from traditional viewpoints, making the study of the rebound effect more comprehensive and meaningful for environmental assessment and policy making. However, the broadened scope of this new approach unveiled some conceptual inconsistencies, which calls for a common framework. This framework would help the LCA community to consistently integrate the rebound effect as well as to create a common language with other disciplines, favouring learning and co-evolution. We believe that our findings can serve as a starting point in order to delineate such a common framework.

Keywords Industrial ecology $\cdot$ Life cycle assessment . Literature review $\cdot$ Rebound effect $\cdot$ Secondary effects . Sustainable consumption

\section{Introduction}

Since the so-called rebound effect was initially operationalised within the energy economics field more than three decades ago (Brookes 1990; Khazzoom 1980) ${ }^{1}$, it has been applied in a manifold of disciplines, such as transport economics or environmental sciences. These disciplines offered new approaches which favoured an asymmetrical evolution of the rebound effect principle. In particular, some researchers from the industrial ecology and life cycle assessment (LCA) communities have embraced with great interest such principle, since it permits more comprehensive environmental assessments and to obtain deeper insights into the drivers behind environmental impacts. However, the inclusion of the rebound

\footnotetext{
${ }^{1}$ A general definition and the description of the main types of rebound effects identified in literature can be found in Sect. 2.
} 
effect into LCA-based studies is still one of the most relevant unresolved issues in the field. While some authors already pointed out the need to tackle this issue during the 1990s (Ekvall 2000; Goedkoop 1999; Weidema 1993), there is currently no consensus on the theoretical principles governing the rebound effect. Attention from the LCA community to the rebound effect is currently scarce but progressively increasing, and only few studies provide quantitative estimates (mostly for carbon dioxide $\left[\mathrm{CO}_{2}\right]$ and global warming potential [GWP]).

The results from those LCA-based studies that have assessed the rebound effect indicate that this exists and can play an important role (see Sect. 3). The rebound effect can be either positive or negative ${ }^{2}$, and can even exceed the magnitude of the initial results ("take-back" or "backfire" effect; Saunders 2000). The rebound effect presents complex challenges if absolute environmental improvements are desired rather than relative environmental improvements. The relevance of these findings is magnified by the fact that LCA results are increasingly being incorporated as a policy support information (Pothen 2010). Incorporating the rebound effect in LCA-based studies in a sound way is thus of critical importance.

While a number of LCA-based studies have considered such effects in a different way, no generally applicable guidelines have been developed so far (de Haan 2008; Girod et al. 2011; Heijungs et al. 2009; Pothen 2010). One of the main reasons behind such a lack of guidelines is the comprehensiveness of the LCA framework, which has permitted to broaden the rebound concept from energy economics (Girod et al. 2011; Hertwich 2005; Hofstetter et al. 2002; Hofstetter and Madjar 2003; Murray 2013; Takase et al. 2005; Thomas and Azevedo 2013a). Consequently, a panoply of nonconsensual definitions and analytical approaches have arisen within the LCA community, and rebound effects have been both unevenly and inconsistently incorporated into LCAbased studies (de Haan et al. 2005; Zamagni et al. 2008). Such asymmetries can lead to double-counting and/or incomparability issues when comparing the results from different assessments (de Haan et al. 2005). Another reason is that communication between the two research fields is far from being fully functional, and the findings from both disciplines are rarely discussed in a common arena. To overcome these setbacks, there is a need for a comprehensive knowledge on the state of play on how the rebound effect has been incorporated into LCA-based studies. This knowledge can serve as a starting point in order to outline common guidelines.

\footnotetext{
${ }^{2}$ Although initially the rebound effect was conceived as a positive change (increase) in consumption, some scholars have theorised a negative rebound effect following the same mechanics (Binswanger 2001), for instance, in those cases in which the technological change entails a decrease in income (more expensive technology), leading to reduced consumption.
}

A number of insightful attempts to survey how the industrial ecology and the LCA communities have tackled the rebound issue can be found in literature (Girod et al. 2011; Hertwich 2005; Murray 2013; Thomas and Azevedo 2013a; Zamagni et al. 2008). However, a comprehensive literature review examining all relevant studies has never been carried out. We argue that, by performing such a review, a more informed discussion can be outlined in terms of identifying the main inconsistencies and gaps present in literature as well as bringing together the various advantages of the life cycle perspective.

This article has two main aims:

- To carry on a literature review to describe the state of play on how the rebound effect has been incorporated into LCA-based studies

- To identify the main strengths of the life cycle perspective and the main issues in current LCA-based studies

\section{General introduction to the rebound effect}

The energy economics literature contains multiple definitions for the rebound effect (Berkhout et al. 2000; Brookes 1990; Dimitropoulos and Sorrell 2008; Greening et al. 2000; Khazzoom 1980; Sorrell 2007). A possible definition that can encompass all of them is the following: The rebound effect is the change in overall consumption and production due to the behavioural or other systemic response to changes in economic variables (income, price and financial gains or costs of product and material substitution) induced by a change in the technical efficiency of providing an energy service $^{3}$. According to the analytical boundaries, Greening et al. (2000) provided a generally accepted decomposition of the rebound effect into four effects: (1) direct effect, (2) indirect effect, (3) economy-wide or structural effect and (4) transformational effect. These single effects can be defined as

Direct effect: Change in the individual consumption or production of an energy service as a behavioural response to a change in economic variables induced by a change in the technical efficiency of providing the same energy service

Indirect effect: Change in the individual consumption or production of other goods and services (different from the improved energy service) as a behavioural response to a change in economic variables induced by a change in the technical efficiency of providing an energy service

\footnotetext{
${ }^{3}$ The rebound effect framework from energy economics is framed within neo-classical economic principles (Berkhout et al. 2000). It thus bears noting that the representation of consumer behaviour from economic models is limited by the simplifications of such principles (e.g. choices made under full relevant information).
} 
Structural effect: Change in the overall consumption and production as a systemic market response to changes in aggregated total demand induced by a change in the technical efficiency of providing an energy service

Transformational effect: Change in the overall consumption and production as a systemic societal response to changes in consumers' preferences, social institutions or the organisation of production induced by a change in the technical efficiency of providing an energy service

These effects can also be classified according to their associated analytical boundaries. A first classification can relate to the time scale considered, whether this is short or long term. That is, whether the time span is long enough to allow changes in consumers' behaviour, alter social institutions or rearrange the organisation of production (Greening et al. 2000) or just adjustments in the economic relationships due to changes in supply and demand. It bears noting that the concept of short term typically encompasses a time scale that includes both short term and mid-term according to the classic economic literature. A second classification is related to the underlying economic perspective, whether it is microeconomic or macro-economic. A micro-economic analysis is concerned with individual markets for goods and services, a macro-economic analysis with the economy as a whole. A macro-economic analysis thus considers the interactions between different markets including labour markets and financial markets. A third classification is about the causal relationship between the technical change and the change in demand for different goods. That is whether the analysis considers only the demand of the process or product that has been changed (direct causality) or also the demand of other processes or products which have not been changed but whose consumption is affected by the energy efficiency change of the focal product (indirect causality). After applying the above mentioned three classifications, the four effects can be depicted as in Fig. 1. These effects are generally connected (and calculated) through a certain sequence: the technical change occurs at the product or process level, causing a behavioural response at the micro-level through a change in demand for the same product (direct effect) and a consequent change in the demand for other products (indirect effect). The sum of micro-level demand changes gives rise to changes in the micro-economic market structures, which leads to further changes in production and consumption at the macro-level (structural effect). Changes in the macro-economic market structures can cause more profound changes in other societal structures (e.g. social or political institutions or sociotechnical regimes) in the long term (transformational effect). Of course, such changes are co-produced, and one important avenue for rebound analysis is to study and reveal the coproduction element (which has to do with economic framework conditions, infrastructures in place, rules and regulations, consumer preferences, product stocks and established practices such as car driving). It is wrong to think that an energy efficiency change will cause a transformative change: It is an element of a broader process, raising important issues of attribution of causal effects. The rebound effect will differ across places (between national and within nations) and is not something purely deterministic. Scenario analysis can capture the non-deterministic element and include relevant contextual factors into the analysis.

\section{LCA-based rebound effect assessments: a review}

\subsection{Review method}

The targeted scientific documents (peer-reviewed scientific articles as well as academic and official reports) are those relevant for the integration of the rebound effect into LCAbased studies. This includes both specific case studies presenting quantitative estimates of the rebound effect through a life cycle perspective as well as relevant literature in terms of providing a conceptual and/or a methodological framework for the integration of the rebound effect into LCA-based studies. The search was conducted using two approaches:

- Via online catalogues (Google Scholar and ISI Web of Knowledge) using a search criterion based on all the possible combinations of the following keywords anywhere in the document: "rebound effect", "LCA" and "life cycle assessment"

- Via cross-citation analysis from the documents identified through the previous approach ${ }^{4}$

The search identified a total of 42 relevant scientific documents, from which 17 provided quantitative estimates of the rebound effect using LCA-based approaches (see Table 1 for a summary and Fig. 2 for a graphical representation). From the 17 studies that provided quantitative estimates of the rebound effect, 12 studies ( $71 \%$ from the total) appraised direct effects, $14(82 \%)$ appraised indirect effects, $3(18 \%)$ appraised structural effects and $1(6 \%)$ appraised transformational effects ${ }^{5}$. The case studies were focussed on transport ( 8 studies, $47 \%$ from the total), energy services $(5,29 \%)$, food (4, $24 \%$ ), general final consumption $(2,12 \%)$ and information and communication technologies (ICT) $(1,6 \%)$. The main environmental indicators used were GWP (11 studies, $65 \%$ from the total), $\mathrm{CO}_{2}$ emissions $(6,35 \%)$ and primary energy $(2,12 \%)$, and multiple indicators were presented in 5 studies ( $29 \%$ from the total). Pressure indicators were calculated in 7

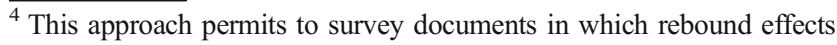
are not explicitly mentioned due to the use of alternative terminologies (such as "ripple" effects [see Sect. 3.2]).

${ }^{5}$ Categories are not exclusive and may be present in various studies simultaneously.
} 
Fig. 1 Graphical classification of the rebound effect according to the analytical boundaries

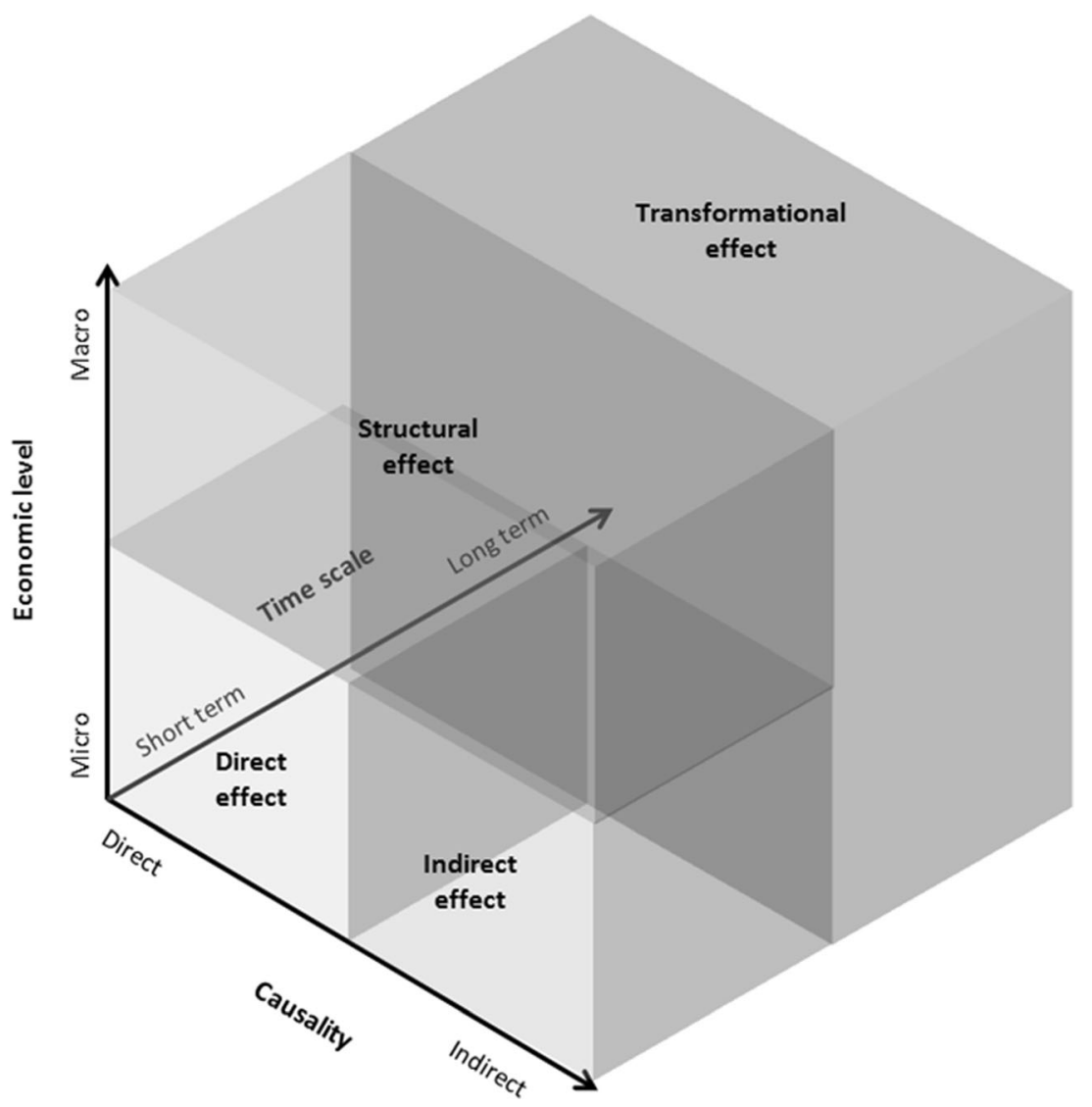

studies (41\% from the total), mid-point indicators in 11 $(65 \%)$ and end point indicators in only $1(6 \%)$.

\subsection{Literature review}

In this section, a literature review of relevant scientific documents on the state of play on how the rebound effect has been incorporated into LCA-based studies is presented. The review is structured according to various topics of interest, ranging from the first attempts at integrating consumer and market behaviour to methodological advances in the calculation of the rebound effect through LCA-based approaches. Complementing the full-text review presented in the following, Table 2 shows a summary with the most relevant contributions according to the selected topics.

\subsubsection{Integrating consumer and market behaviour into LCA studies}

By the early 1990s, the energy economics literature already provided a fairly sound methodological framework to appraise the rebound effect at both micro- and macro-economic levels, with quantitative estimates for multiple energy services, such as heating or transport (Greening et al. 2000). At the same time, some authors from the industrial ecology and LCA fields, such as Weidema (1993), stressed the need to consider market information when building the life cycle inventory (LCI) of products, arguing that such consideration would bring more realism and accuracy into the LCA results. While the rebound effect was not explicitly mentioned, the argumentation that the demand for services from products was determined by market conditions was a stepping stone to the integration of the rebound effect into LCA-based studies later on. This idea was further developed some years later by Goedkoop et al. (1998) and Goedkoop (1999), which advocated for determining the functional unit based on the observed consumer and producer's behaviour, rather than arbitrarily. By using observed behaviour data, two main outcomes arise: First, changes in demand due to the direct rebound effect are incorporated and, second, changes in different ancillary product systems can be assessed, offering a broader picture to potentially assess other causal effects. However, an important setback of such an approach is that it is difficult to differentiate the rebound effect from other determinants of demand, such as economic growth or policy measures. In any case, this understanding of a dynamic demand, constrained by both consumer and market behaviour, as well as the explicit mention to the rebound effect, can be considered the seed of the integration of the rebound effect into LCA. Moreover, Ekvall (2000) theorised that indirect effects caused by market behaviour could be considered by means of system expansion, and started to develop guidelines to potentially appraise the 


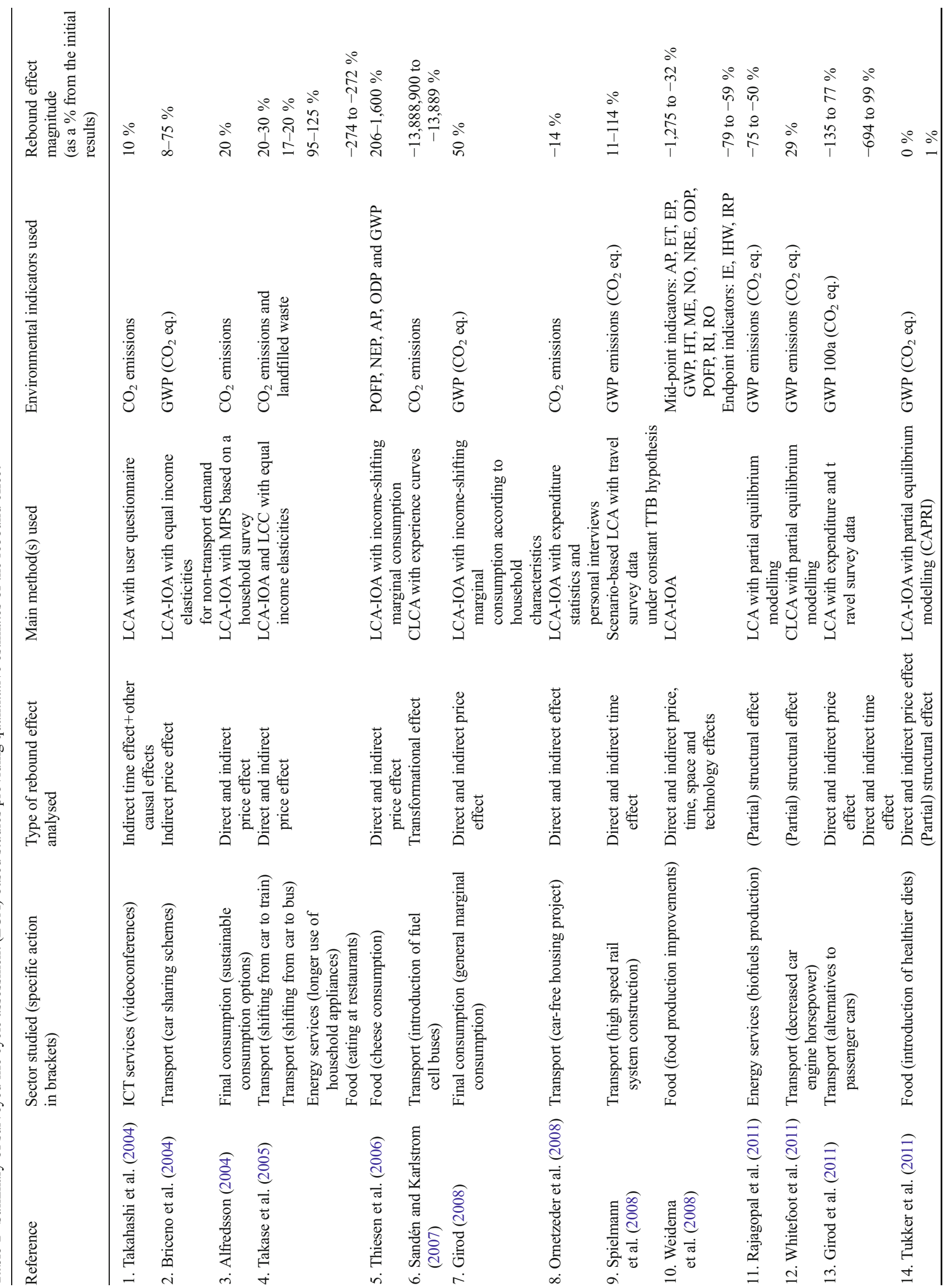




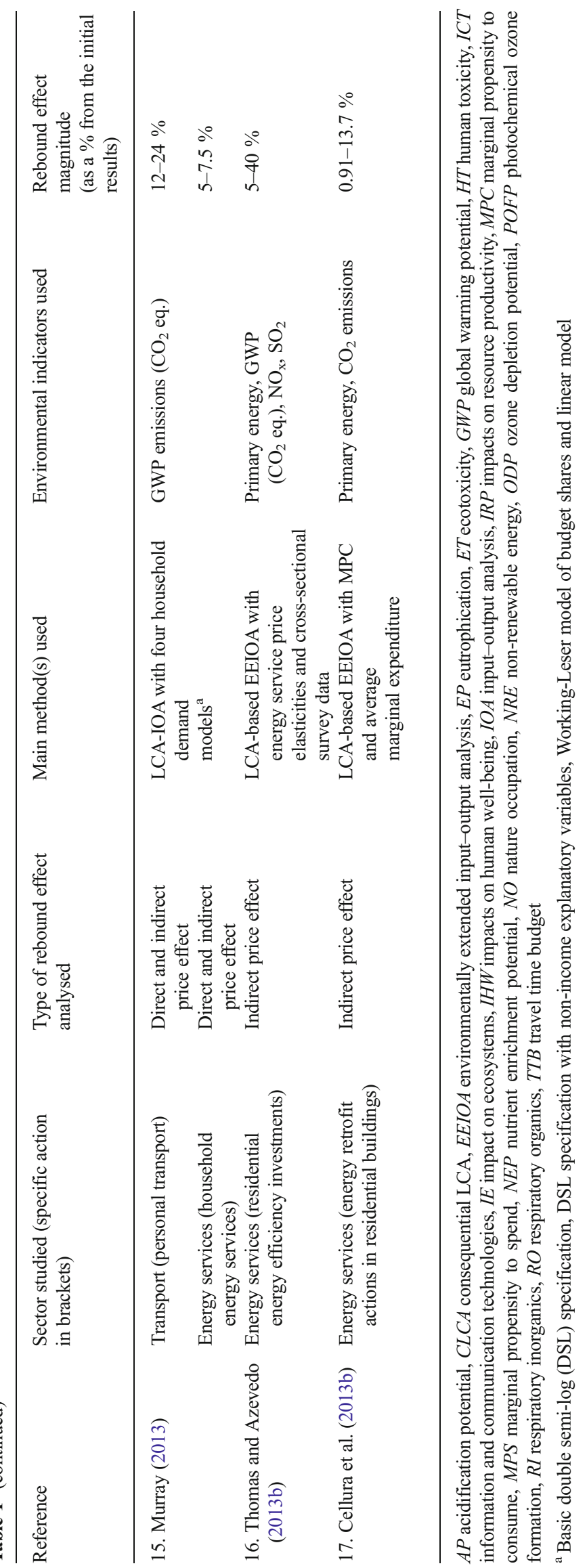


Fig. 2 Graphical representation of life cycle assessment (LCA)based rebound effect studies according to the analytical corresponds to a study referenced in Table 1. Asterisk indicates that, in these studies, direct effects were neglected. Dagger indicates that these studies used partial equilibrium models; hence, only an individual market was that the prices for the rest of the markets would remain constant. Because of this, the causality is considered to be direct boundaries. Each number considered and it was assumed

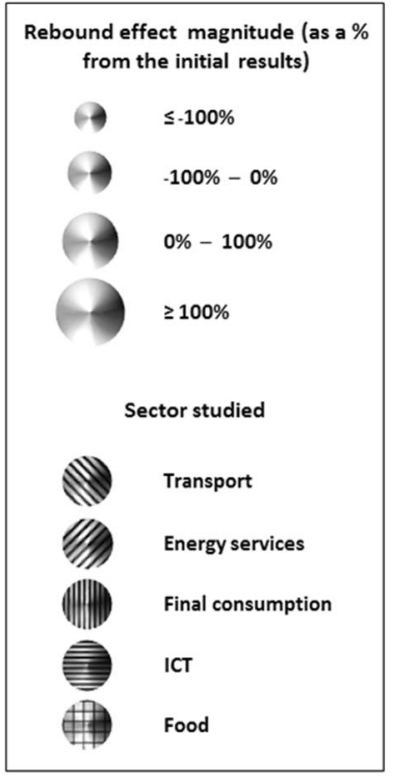

rebound effect through the emerging consequential LCA (CLCA) approach (Ekvall 2002).

\subsubsection{Broadening the definition of the rebound effect}

Once the rebound effect was considered relevant for LCA, the comprehensiveness of the LCA framework and its use for broad-scoped sustainability assessments facilitated the broadening of some aspects from the original definition of the rebound effect from energy economics (see Sect. 2). Provably, the most explicit change was that the rebound effect was defined not only by changes in energy use but also by multiple environmental metrics (Hertwich 2005). Because of this, Goedkoop (1999) coined the term "environmental rebound effect", which has been commonly used. Another change focussed on the drivers behind the rebound effect, which no longer were reduced to economic variables (see Sect. 3.2.3). Lastly, some scholars also challenged the idea that only changes in the efficiency of providing a service could cause the rebound effect, and argued that other mechanisms could come into play.

In this sense, Hertwich (2005) undertook a literature review on how the rebound effect was treated in both the energy economics and the industrial ecology fields, arguing that the definition of the rebound effect provided by energy economics was insufficient to describe all the secondary effects which are of interest to the industrial ecology and LCA fields. For instance, behavioural and technological spillovers, transformational effects or "positive" side effects would not be included. Instead, he advocated for the use of the term "ripple" effect, which had been used previously by Hofstetter et al.

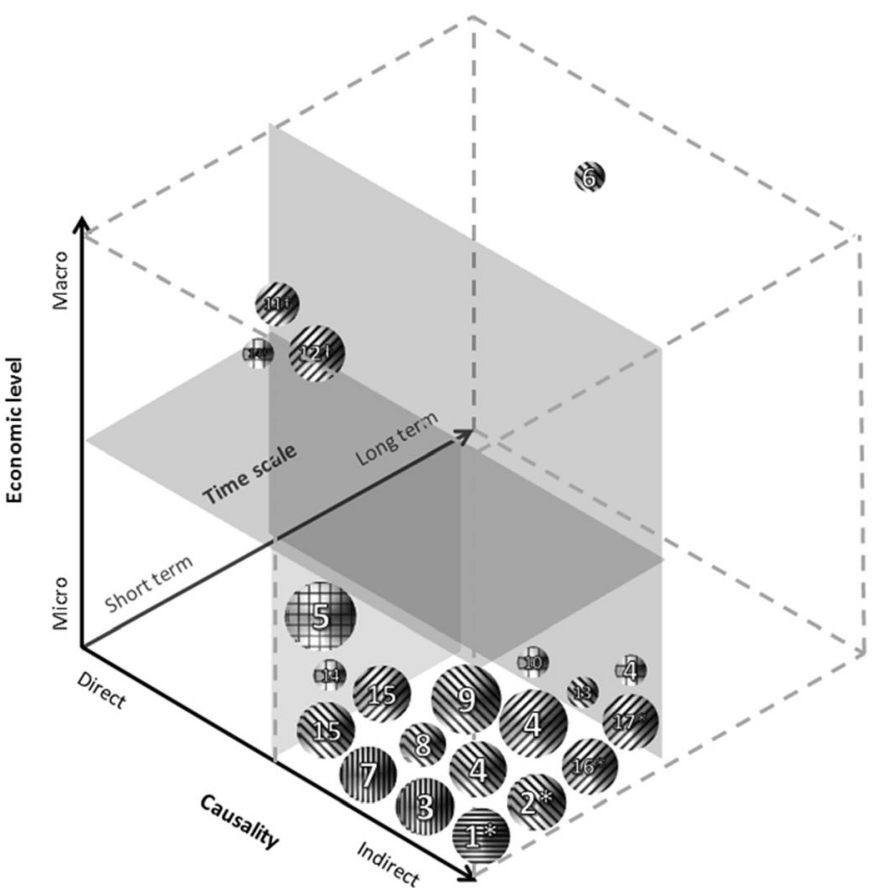

(2002). Weidema et al. (2008:61) proposed a rather broad definition of the rebound effect as "the derived changes in production and consumption when the implementation of an improvement option liberates or binds a scarce production or consumption factor", in what can be considered as an attempt to balance the industrial ecology perspective with the basic rebound principles identified in energy economics. The term "improvement option" would thus permit to account for a wide range of effects derived not only from changes in service efficiency but from broader product modification (e.g. material substitution) or product substitution. In the same line, Girod et al. (2011:5) defined the rebound effect as "the consumption feedback loops of product modification [...] or replacement", in an exercise to provide stepwise guidelines to integrate direct and indirect price rebound effects into LCA studies. This definition allows for full product substitutability, that is, without considering service or function comparability. Lastly, Murray (2013) argued that the rebound effect can arise from both efficiency and conservation decisions, that is, from a lower use of a given product.

\subsubsection{Broadening the consumption and production factors}

While, according to energy economics, the rebound effect is generally triggered by economic factors (usually income or prices), industrial ecology and LCA scholars started to include a wider range of consumption factors as possible drivers. In this sense, Hofstetter and Madjar (2003) introduced some innovative concepts and recommendations for the LCA field while assessing sustainable consumption patterns. Based on previous studies, they argued that there exist several 
Table 2 Summary of the most relevant contributions to the assessment of the rebound effect through the LCA framework

\begin{tabular}{ll}
\hline Study & Main contribution \\
\hline $\begin{array}{l}\text { Topic: integrating consumer and market behaviour in LCA studies } \\
\text { Weidema (1993) } \\
\text { Product demand is determined by market conditions. Market information must thus be considered during } \\
\text { the LCI stage } \\
\text { Both consumer and market behaviour determine the demand for products and must be studied within the LCA } \\
\text { framework }\end{array}$ \\
Indirect effects caused by market behaviour can be considered by means of system expansion
\end{tabular}

Topic: broadening the definition of the rebound effect

Goedkoop et al. (1999)

Alfredsson (2004)

Hertwich (2005)

Weidema et al. (2008)

Murray (2013)

Topic: broadening the functional unit

Goedkoop (1999)

Hofstetter and Madjar (2003)

Weidema and Thrane (2007)

Topic: broadening the consumption and production factors

Hofstetter and Madjar (2003)

De Haan et al. (2005) and Hofstetter et al. (2006)

Weidema and Thrane (2007)

De Haan (2008)

The broader scope of LCA allows for the study of "environmental rebound effects", which can be represented as changes in multiple environmental loads rather than only energy use

The rebound effect can be caused by technology modification (same function) as well as technology substitution (different function)

The traditional definition from energy economics is insufficient to describe all the secondary effects that are of interest to industrial ecology (e.g. technology spillovers). Instead, a broader concept (ripple effect) should be used

The rebound effect can be induced not only from efficiency increases but also from technology improvements in a broader sense (e.g. material substitution)

The rebound effect can be caused by both efficiency (same output) and conservation decisions (less output)

The functional unit must be determined through observed demand data rather than arbitrarily, thus allowing for the assessment of the rebound effect from consumer and market behaviour

Because consumers seek utility rather than product functional outputs, the functional unit should be based on utility levels in order to represent more accurately product demand and improve the assessment of the rebound effect

Instead of product functional outputs, functional units should be defined in terms of broader functions that can be fulfilled by substitutable product alternatives in order to fully account for the rebound effect

Rather than just money, six consumption factors leading to rebound effects can be determined: money, information, resources, space, time and skills

Socio-psychological costs or can be considered a consumption factor and changes in those can induce a sociopsychological rebound effect

Technology availability can be considered a consumption factor potentially leading to the rebound effect

Changes in technical definitions can cause competitive advantages to technologies, causing a regulatory rebound effect

Topic: methodological advances in LCA

Ekvall (2002) and Pothen (2010)

Briceno et al. (2004)

Structural environmental rebound effects can be calculated by linking the process tree of an LCA with a CGE model. The linkage can be in the form of connected models (softlinking) or through a unique model (hardlinking)

The use of hybrid LCA increases the technology explicitness when modelling the indirect price environmental rebound effect. The results in the form of end point environmental impact indicators provide deeper insights for environmental assessment

Takase et al. (2005)

Describing the environmental rebound effect in the form of multiple environmental indicators permits to assess trade-offs between indicators

Kondo and Takase (2007)

Sandén and Karlstrom (2007)

Whitefoot et al. (2011)
By combining hybrid LCA with price modelling, structural effects can be appraised while maintaining the technology detail of LCA

Transformational effects can be appraised by combining LCA with theories of technical change

Price rebound effects from changes in product design can be assessed by means of CLCA and partial equilibrium modelling

$C L C A$ consequential life cycle assessment, $C G E$ computable general equilibrium, $L C A$ life cycle assessment, $L C I$ life cycle inventory

determinants of demand or consumption factors, narrowing them down to six following the rationale that these are of immediate relevance to personal consumption: money, information, resources, physical space, time and skills. Moreover, they argued that any change in these factors can lead to a rebound effect, and exemplified this by providing 
some analytical guidelines to calculate a time rebound effect (based on previous works, for instance, by Binswanger (2001) or Jalas (2002)) using LCA data. The general guidelines provided by Hofstetter and Madjar (2003) to calculate a time rebound effect were later further developed into a general method by Spielmann et al. (2008), which they then applied in a case study on the hypothetical construction of a highspeed train in Switzerland.

De Haan et al. (2005:595) also embraced the idea of a broadened scope of the rebound drivers and introduced the idea of a socio-psychological rebound effect, which would be related to the change in the "social cost and/or the psychological cost attributed to the consumption of a given service". The authors attempted to obtain evidence of this effect by studying the direct effect from hybrid cars (that is, whether people drove more or increased the number of cars owned due to the higher social acceptance and alignment with the environmental conscience of individuals) but found no evidence of such effect. Hofstetter et al. (2006) stretched even more the rebound drivers and argued that not only social status and environmental conscience determine consumption but that this also depends on the fulfilment of needs and the achievement of happiness and quality of life, and coined the psychological rebound effect concept. According to the authors, the psychological rebound effect could be differentiated from the "physical" rebound effect, which stems from the consumption or "limiting" factors they had previously identified (Hofstetter and Madjar 2003). This thesis was built upon the premise that a saturation point for the willingness to increase utility can be reached. In other words, "the better an activity, product, or service satisfies basic needs and maximises ultimate utility, the lower the propensity for more (material) consumption" (Hofstetter et al. 2006:108). However, as the authors point out, there is yet scarce empirical evidence in the literature to validate such statement. De Haan (2008) also described a "regulatory" rebound effect, caused by technical definitions in favour of new technologies, providing them with competitive advantages that induce extra demand. Weidema and Thrane (2007) also contributed to this topic by proposing to include "technology availability" as a consumption factor, arguing that new technologies may affect the availability of other technologies or raw materials. For instance, home delivery services would have the potential to decrease car ownership (Weidema and Thrane 2007).

\subsubsection{Broadening the functional unit}

The conception of the demand for products as a dynamic element, influenced by consumers and market behaviour, resulted in a reinterpretation of the functional unit concept in comparative LCA studies, which traditionally was static and arbitrary. This shift was initiated when Goedkoop (1999) argued the use of functional units based on empirical evidence rather than arbitrarily to capture the rebound effect. For instance, when comparing two vehicle technologies, one should reflect observed differences in driving behaviour in the functional unit, which no longer needed to be equal for all alternatives. Influenced by this work, Girod et al. (2011) presented the "consumption as usual" concept to introduce a dynamic demand in comparative LCA, which was based on two assumptions: (1) "the total of household resources used for consumption does not change subsequent to product modification" and (2) "the preference for allocations of household resources to different purposes does not change subsequent to product modification" (Girod et al. 2011:6). The authors advocated for compiling information on household constraints during the life cycle inventory (LCI) stage and calculating the functional units with the help of econometric and other economic tools. They applied this approach in a case study on alternative transport technologies to car travel and calculated the direct and indirect price and time rebound effects under different assumptions. Weidema and Thrane (2007) advocated for a rather broad definition of the functional unit to account not only for changes in demand for products but also for alternative products or consumption patterns. Thus, functional units in the form of "average use of cars", such as proposed by Goedkoop (1999), would not be able to fully account for environmental improvements. Instead, a functional unit such as "a means of passenger transport" or even wider as "a means of co-locating a person with a desired object, activity or (group of) person(s)" would allow to include non-transport alternatives, such as telecommunication, to fulfil the co-location need (Weidema and Thrane 2007:2). Hofstetter and Madjar (2003) went further and advocated for shifting from a function to a utility approach in LCA (thus comparing product systems in terms of a common utility level), aiming at a more accurate representation of product demand and the rebound effect. The authors supported this approach by arguing that consumers ultimately seek utility rather than products or end services.

\subsubsection{Methodological advances in LCA}

The methodological approaches to quantitatively assess the (environmental) rebound effect through LCA-based methods have evolved by integrating advances from both the industrial ecology and LCA fields as well as from other disciplines. The MARKAL model, an economic analysis tool from the International Energy Agency (IEA) (Fishbone and Abilock 1981; Manne and Wene 1992; Seebregts et al. 2002), can be considered the first approach. Taking advantage of the emergence of LCA data during the late 1990s (Ybema and Kram 1997), the inclusion of LCA data into this model permitted "to include materials and product substitutions, alternative waste management options, recycling and re-use to be assessed in 
direct relation with energy production and use" (Ybema and Kram 1997:18). Another inceptive study was that of Durrenberger et al. (2001), which investigated the impact of the rebound effect due to commodity consumption growth in terms of embodied energy (based on LCA data) in household energy consumption in Switzerland, concluding that the rebound effect started to be observed when the annual growth of per capita consumption was projected to increase by $0.3 \%$ as a result of energy efficiency increases. However, the definition of the rebound effect in this study was somewhat vague in the sense that it is not clear which type of effects were actually assessed. Erdmann et al. (2004) presented a model for calculating a number of life cycle environmental indicators for ICT considering the direct price rebound effect using empirical demand elasticity values. Quantitative estimates of the magnitude of such effect were, however, not provided. Takahashi et al. (2004) combined LCA and model analysis based on a user questionnaire to calculate the rebound effect of ICT services in terms of $\mathrm{CO}_{2}$ emissions, in a case study on videoconferences. They used a rather broad and unspecific definition of the rebound effect based on causal relationships at the microeconomic level, which included a combination of indirect time effects and other effects linked to gained and lost opportunities and benefits.

A more robust and conceptually defined study was conducted by Briceno et al. (2004), which calculated the indirect price rebound effect using an hybrid LCA framework (Suh and Huppes 2002) in a case study of car sharing in Norway with different scenarios based on travel behaviour. In their study, the entire change in income was allocated to nontransport expenditure; hence, the direct rebound effect was neglected. To model the indirect effect via marginal consumption expenditure, they assumed equal income elasticities for all described goods of final demand, again an unrealistic assumption. The authors used GWP as an environmental indicator, calculated in kilograms of $\mathrm{CO}_{2}$ equivalent. The relevance of this work lays first in the fact that it is the first to use hybrid LCA to appraise the income rebound effect and, second, it is also the first to provide quantitative estimates using end point environmental impact indicators. Alfredsson (2004) studied green consumption patterns in Sweden using LCA data and devised a more realistic way of modelling marginal consumption expenditure than assuming equal income elasticities (Briceno et al. 2004; Takase et al. 2005), using empirical data from household surveys, which were classified into three income groups. A similar approach was applied by Thiesen et al. (2006), who modelled shiftings between expenditure structures by income quintiles. Using hybrid LCA, the authors calculated the income rebound effect for five mid-point environmental indicators, which then applied to a comparative LCA of the consumption of two types of cheese in Denmark. Girod (2008) and Girod and de Haan $(2009,2010)$ argued that the approach used both by
Alfredsson (2004) and Thiesen et al. (2006) disregarded the influence that the household structure could have on marginal expenditure, and proposed to combine the affluence parameter with household structure data. Moreover, this model was based on functional units instead of monetary units, which had been proposed before by Hertwich (2005). A sensitivity analysis revealed a number of valuable insights (Girod 2008). First, using monetary units instead of functional units increased marginal emissions due to the fact that wealthier households would pay higher prices for the same amount of functional units. Second, disregarding the household structure led to increased marginal emissions because of saturation thresholds. Third, a lower detail of the consumption categories entailed a decrease in marginal emissions, since shifting towards more expensive and more carbon intensive products due to higher income would not be captured. An alternative approach to model marginal consumption was applied by Ornetzeder et al. (2008), which used a combination of expenditure statistics and personal interviews (including access to the utility bills) on a case study on a car-free housing in Austria. Due to the different possibilities to model marginal consumption, Murray (2013) used hybrid LCA to calculate the income rebound effect from personal transport and household energy services using various household demand models. The results described a notable influence of the demand model choice, as well as other assumptions such as the household income and characteristics.

Weidema et al. (2008) calculated a combination of the main identified direct and indirect rebound effects based on four demand factors (money, time, space and technology availability) of different improvement options for meat and dairy product production in Europe using (for the first time) a combination of 15 mid-point categories and 3 end point categories. Thomas and Azevedo (2013a, b) also appraised the income rebound effect using an LCA-based environmentally extended input-output table (EEIOT) and a combination of energy service price elasticities and cross-price elasticities from cross-sectional survey data. Cellura et al. (2013a, b) appraised the indirect price rebound effect of a tax deduction policy for energy retrofit actions of buildings in Italy using LCA-based EEIOA in combination with an average marginal expenditure approach based on various marginal propensity to consume (MPC) scenarios.

Takase et al. (2005) appraised the income rebound effect using the waste input-output (WIO) model, a hybrid LCA and life cycle costing (LCC) tool which includes waste treatment sectors. The authors used $\mathrm{CO}_{2}$ emissions and landfilled waste as indicators, being the first study providing estimates of the rebound effect through multiple indicators. Later on, the WIO model was refined by introducing a component to model consumer behaviour, in which both income and time aspects were considered (Kondo and Takase 2007; Takase et al. 2006). To model consumption behaviour, the concept of 
"consumption technologies" was introduced (Becker 1965), through which "given prices, income, and time, a consumer is assumed to choose a set of activity levels of various consumption 'technologies' to maximise her/his utility" (Kondo and Takase 2007:3). The model also permits to model product price's changes as a result of changes in the rates of recycling, which are dependent on the consumer's lifestyles (mix of consumption technologies). This feature permits to consider the WIO model as a very simplistic version of a computable equilibrium model. Because of this, the authors claimed that the model permits to partly account for the structural rebound effect. The work by Kondo and Takase (2007) was the first attempt to model structural effects through an LCA-based approach. Another approach to assess structural effects using LCA data can be found in the work of Rajagopal et al. (2011), which used a partial equilibrium model to calculate the rebound effect from the introduction of biofuels in the USA.

Whitefoot et al. (2011) designed a novel approach combining CLCA and a partial equilibrium model to account for the direct price rebound effect from product design changes. The authors called the model CLCA-market driven design (MDD) and applied it in a case study on a decision on decreasing a car engine horsepower. As a response to this change, the model was able to determine the equilibrium horsepower for competing vehicles and the equilibrium prices for all vehicles, which in turn would define the product and use demand for all vehicles. Tukker et al. (2011) also combined a partial equilibrium model, in this case the CAPRI model for the agricultural sector (Britz et al. 2010), with hybrid LCA in order to account for income and structural effects from the introduction of healthier diets in Europe. LCA data was also used in this study to increase the detail of the E3IOT (Huppes et al. 2006), an EEIOT, to the product level, thus improving the technology specification of the equilibrium modelling exercise (Huppes et al. 2006). A computable general equilibrium (CGE) model (GTAP [Hertel 1999]) was combined with LCA data by Dandres et al. (2011) on a case study on bioenergy policies in Europe, and a structural rebound effect was claimed to be identified by the authors, concretely a $7 \%$ increase in lignite production due to the reduction of supply prices. However, as the authors point out, deeper insights into the identified rebound effect were not achieved because of the complexity of the GTAP model.

The combination of LCA with computable equilibrium models was firstly theorised by Ekvall (2002), who proposed to link the process tree of an LCA to a CGE model to account for structural effects. He also discussed the possible ways to apply such linkage between bottom-up (LCA) and top-down (CGE) models based on the energy system modelling literature, concretely on the works of Manne and Wene (1992) on the MARKAL model. Two paths were devised: softlinking and hardlinking. In the first, the results from one model are manually fed into the other, whereas, in the second, the two models are integrated to become a single model. The author described the strengths and weaknesses of both approaches for LCA, concluding that softlinking could aid to reduce the issue of increasing complexity if both LCA and CGE models are integrated. Pothen (2010) also provided a number of guidelines in order to combine LCA with CGE through which he called a "Life Cycle Based Computable General Equilibrium Model". He also opted for a softlinking approach, arguing that it would avoid an increase in complexity, make interpretation and critique for every step possible and reduce cost and effort for the analyst.

Sandén and Karlstrom (2007) explored the possibilities of combining CLCA with theories of technical change (Freeman 1998; Parke 1987) in order to study what they called "thirdorder consequences". These consequences would go beyond cause-effect relationships between supply and demand (structural effect) and would describe the change in the availability and cost of technologies and in actor's preferences as a result of the cumulative buildup of stocks and structures. This type of effect has been described in literature as a transformational effect (Greening et al. 2000; Polimeni et al. 2008; RamosMartin 2003). The study appraised such transformational effect using scenarios and experience curves to quantify the potential $\mathrm{CO}_{2}$ emissions reductions from the use of fuel cell buses. The authors made a plea that LCA studies aiming at assessing strategic technology choices should "not only include effects resulting from marginal change of the current system but also marginal contributions to radical system change" (Sandén and Karlstrom 2007:1479). The work by Sandén and Karlstrom (2007) can thus be regarded as the first attempt to appraise the transformational effect from a life cycle perspective.

\section{Strengths of the life cycle perspective to assess the rebound effect and myth busting}

\subsection{Strengths of the life cycle perspective}

The life cycle perspective permits researchers to approach the rebound effect more comprehensively. In the following, we elaborate in detail this statement by discussing the main aspects in which LCA-based approaches may contribute to the general rebound effect literature.

\subsubsection{Multi-dimensional life cycle environmental indicators}

Energy economics studies usually consider only direct pressures (energy use and combustion emissions from product use and/or purchased electricity) from the products or capital in which the improvement option takes place for their rebound effect estimates (Thomas and Azevedo 2013a). Because of 
this, some authors argue that the embodied pressures (from upstream and downstream processes) of improved products and capital comprise itself a rebound effect, for instance in the form of an "embodied energy effect" (Sorrell 2009; van den Bergh 2011). However, according to the rebound principle, relative embodied pressures (pressures per unit of demand) are not triggered by behavioural or systemic responses but are a result of the technological characteristics of products and supply chain processes, and are thus necessary and inseparable from the improved products and capital (Murray 2013). We thus argue that embodied-type effects have no conceptual basis to be regarded as a rebound effect. This conflicting viewpoint emerged already in the first LCA-based environmental rebound effect assessments, which used embodied energy as an indicator (Durrenberger et al. 2001).

Assessing the rebound effect through a life cycle perspective may also help in weighting the relative importance of direct and indirect effects. For instance, the indirect effect may be relatively more relevant than previously thought, as LCAbased studies suggest that the energy input related to household expenditure may play a bigger role with respect to the direct energy use from final consumption (electricity, motor fuels, etc.) (Murray 2013). Moreover, the computational structure of LCA and the availability of databases make it possible to calculate results using multiple environmental indicators and from different levels of the society-environment interaction (e.g. pressure, mid-point or end point) (see Table 1), which permits researchers to identify possible trade-offs between indicators (e.g. presence of both positive and negative rebound effects in different indicators) (Girod and de Haan 2010; Hertwich 2005).

\subsubsection{Improvement of the technology explicitness}

In energy economics, the atomic level of analysis to characterise causal links is generally sectorial input-output relationships, whereas LCA is process-based. The higher level of technological explicitness permits a manifold of possibilities in terms of increasing the accuracy of rebound estimates as well as identifying new levels of indirect causal relationships. Some of the advantages that such technology explicitness offers are described as follows:

- Technological specification: Rather than using average production, consumption and waste treatment data, changes in specific processes can be identified. Processes can thus be technologically characterised, as well as spatially and temporally. For instance, LCA data can be used to increase the detail of input-output tables (IOTs) to the process or product level, increasing the accuracy of computable equilibrium exercises to appraise structural effects (Huppes et al. 2006).
- Identification of actors along the supply chain: If the specific production and consumption processes along the entire supply chain are known, the identification of the actors related to these processes is facilitated. This feature can help to trace the specific consequences of marginal changes in production or consumption on these actors, for instance by obtaining empirical data. Moreover, by identifying the actors involved in all parts of the life cycle, the process of knowledge generation and technological learning can be better assessed, offering a more comprehensive approach to transformational effects (Sandén and Karlstrom 2007).

- Tracing of external costs: Financial rebound effects are generally approached by quantifying the change in economic internalised costs, that is, those that are directly captured in the form of prices by the market. This approach excludes external costs, that is, those borne by uninvolved parties that do not choose to incur that cost or benefit, and which are generally not captured by the market (e.g. health care and cleanup costs from pollution). In the same way as market costs, external costs can induce a rebound effect as well. For instance, if health care costs increase due to pollution, the income available from those affected for consumption would decrease. By offering a broad range of environmental indicators, as well as technological specification and consequent actor identification, the life cycle perspective of methods such as LCA and life cycle costing (LCC), used in combination, can help to trace and quantify the external costs incurred along the entire supply chain and thus obtain more realistic estimates of the rebound effect that otherwise would be neglected (Hertwich 2005; Roth and Ambs 2004).

\subsubsection{Broadening the consumption factors}

According to the traditional economic theories of choice, households would try to maximise their utility through consumption, with income as the sole limiting factor. Some authors also include time in the utility functions but in the form of a constraint (Becker 1965). Based on this premise, energy economics studies usually state that a price signal should always be present to trigger a rebound effect (Berkhout et al. 2000; Greening et al. 2000). However, some authors argue that "the definition of the rebound effect for itself does not state that a price signal should be present, it merely builds upon changes in energy demand due to changes in energy efficiency" (de Haan 2008:14). In this sense, many authors from a variety of fields, such as transportation studies or social sciences, argue that there exist many other consumption factors apart from income that would determine the level of consumption, such as time, information, skills or physical space (Hofstetter and Madjar 2003), all of which could trigger 
rebound effects. For instance, one can consume "free" products without any individual direct economic cost (e.g. water from a public water fountain). In that case, other limiting factors, such as information or time, should drive the utility maximisation function. Some authors also argue that utility is not what ultimately drives consumption, but rather quality of life, happiness or subjective well-being (Hofstetter and Madjar 2003). As our review points out, some of the researchers that have actively contributed to this line of thought are from the industrial ecology and the LCA communities. Within the latter, the search towards a broader concept of the functional unit to assess sustainability issues led some authors, such as Goedkoop (1999), Kondo and Takase (2007) and Hofstetter and Madjar (2003), to meaningfully contribute to this debate.

\subsection{Myth busting}

By carrying out a comprehensive survey, we can also provide informed counterclaims to some statements found in literature. One recurring claim is that direct and indirect effects can only be appraised through consequential modelling, since they are related to changes in marginal consumption and thus "beyond the computational structure of attributional LCA" (Wood and Hertwich 2013:5). However, Girod et al. (2011) offered a general methodological framework in which both approaches are possible to tackle the rebound effect, and argue that the main difference would be in how the impact intensity of marginal consumption is calculated, due to the processes included in the system. This line of argumentation would be in line with the conclusions reached by Zamagni et al. (2012), which argue that the modelling principles of both approaches are essentially the same. Moreover, some studies have attempted to calculate direct and indirect effects while keeping market structures and without production specification (e.g. by using average marginal expenditure and average impact intensity data, for instance in the works of Briceno et al. (2004) or Takase et al. (2005)), which are among the core principles of CLCA. We therefore consider the claim that only CLCA is able to appraise the rebound effect to be unfounded.

Other authors generalise that industrial ecology studies normally use average consumption data to model marginal consumption (Thomas and Azevedo 2013b). However, that claim is also unfounded based on our literature review, since various studies model marginal consumption according to income group shifting (Girod 2008; Thiesen et al. 2006), household characteristics (Girod 2008; Murray 2013) or expressed preferences through personal interviews (Ornetzeder et al. 2008). While it is true that industrial ecology and LCA studies generally focus on the technology dimension (Font Vivanco et al. 2014), it is not an inherent specification, and, as evidence suggests, demand theories have been progressively included.

\section{Conclusions}

The presented review, which we consider to be more comprehensive than previous attempts in terms of the studies included and the discussion of research choices, contributes a number of valuable insights to understand how the rebound effect has been treated within the industrial ecology and LCA fields. The assessment of strengths and weaknesses is used to make recommendations for future research on environmental rebound effects. In the article, we have identified a number of strengths that the life cycle perspective offers or facilitates to the study of the environmental rebound effect, such as the multi-dimensionality and life cycle perspective, the increased technological explicitness or the broadening of the consumption factors. With these refinements, the study of the environmental rebound effect can become more comprehensive and meaningful for environmental assessment and policy making. Such refinements represent a step forward from the traditional viewpoint of energy economics, which make the contribution of the industrial ecology and LCA fields relevant.

However, we have also identified a number of inconsistencies in the definition of the rebound effect, especially regarding the interpretation of what kind of technological change can cause a rebound effect. For example, some authors have stretched its definition to the point that the functional comparability can be questioned because the functional output of the two alternatives studied is significantly different (e.g. conservation decisions). Others confound the rebound effect with a mere unintended consequence. These new definitions conflict with the core mechanisms of the rebound effect and go beyond simple refinements. Also, not all LCA studies use the same terminology to describe the various effects that comprise the rebound effect. In this sense, there is a need to delineate a common framework in harmony with the core mechanisms behind the rebound effect. This framework would help the LCA community to consistently integrate the rebound effect as well as to create a common language with other disciplines, favouring learning and co-evolution. We believe that our findings can serve as a starting point in order to build such common framework.

This lack of consensus can explain to a great extent why, while holding great potential, the contribution of the industrial ecology and the LCA communities to the general rebound effect literature is currently poorly communicated to other fields such as energy economics, resulting in a more or less parallel development. Indeed, the developments and advantages stemming from the works of these communities seem to be insufficiently regarded within the mainstream rebound effect community. We consider that such disregard justifies and stresses the importance of the present study.

Acknowledgments This research has been undertaken within the framework of the Environmental Macro Indicators of Innovation 
(EMInInn) project, a collaborative project funded through the EU's Seventh Framework Programme for Research (FP7) (grant agreement no. 283002). The authors would like to thank René Kemp, Jaume FreireGonzález and two anonymous reviewers for their comments.

\section{References}

Alfredsson EC (2004) Green consumption: no solution for climate change. Energy 29(4):513-524

Becker GS (1965) A theory of the allocation of time. Econ J 75(299): 493-517

Berkhout PHG, Muskens JC, Velthuijsen W (2000) Defining the rebound effect. Energ Policy 28(6-7):425-432

Binswanger M (2001) Technological progress and sustainable development: what about the rebound effect? Ecol Econ 36(1):119-132

Briceno T, Peters G, Solli C, Hertwich E (2004) Using life cycle approaches to evaluate sustainable consumption programs: car-sharing, reports and working papers from Norwegian University of Science and Technology (NTNU), Industrial Ecology Programme (IndEcol). Working Papers no.2/2005

Britz W, Domínguez I, Heckelei T (2010) A comparison of CAPRI and SEAMLESS-IF as Integrated Modelling Systems. In: Ittersum MK, Brouwer FM (eds) Environmental and agricultural modelling. Springer, Netherlands

Brookes L (1990) The greenhouse effect: the fallacies in the energy efficiency solution. Energ Policy 18(2):199-201

Cellura M, Di Gangi A, Longo S, Orioli A (2013a) An Italian inputoutput model for the assessment of energy and environmental benefits arising from retrofit actions of buildings. Energ Build 62:97106

Cellura M, Guarino F, Longo S, Mistretta M, Orioli A (2013b) The role of the building sector for reducing energy consumption and greenhouse gases: an Italian case study. Renew Energ 60:586-597

Dandres T, Gaudreault C, Tirado-Seco P, Samson R (2011) Assessing non-marginal variations with consequential LCA: application to European energy sector. Renew Sustain Energy Rev 15(6):31213132

De Haan P (2008) Identification, quantification, and containment of energy-efficiency induced rebound effects: a research agenda. Rebound Research Report Nr. 1. ETH Zurich, IED-NSSI, report EMDM1521, 26 pages. doi:10.3929/ethz-a-006224281

De Haan P, Mueller MG, Peters A (2005) Does the hybrid Toyota Prius lead to rebound effects? Analysis of size and number of cars previously owned by Swiss Prius buyers. Ecol Econ 58(3):592-605

Dimitropoulos J, Sorrell S (2008) The rebound effect: microeconomic definitions, extensions and limitations. Ecol Econ 65(3):636-649

Durrenberger G, Patzel N, Hartmann C (2001) Household energy consumption in Switzerland. Int J Environ Pollut 15(2):159-170

Ekvall T (2000) A market-based approach to allocation at open-loop recycling. Resour Conserv Recycl 29(1-2):91-109

Ekvall T (2002) Cleaner production tools: LCA and beyond. J Clean Prod 10(5):403-406

Erdmann L, Hilty L, Goodman J, Arnfalk P (2004) The future impact of ICTs on environmental sustainability. Institute for Prospective Technological Studies

Fishbone LG, Abilock H (1981) Markal, a linear-programming model for energy systems analysis: technical description of the bnl version. Int J Energy Res 5(4):353-375

Font Vivanco D, Kemp R, Van der Voet E, Heijungs R (2014) Using LCA-based decomposition analysis to study the multi-dimensional contribution of technological innovation to environmental pressures. J Ind Ecol 18(3):380-392
Freeman C (1998) The economics of technical change. Trade, Growth and Technical Change, Cambridge, pp 16-54

Girod BV (2008) Environmental impact of Swiss household consumption, and estimated income rebound effects, Eidgen-Âssische Technische Hochschule Zurich, IED-Institute for Environmental Decisions, NSSI-Natural and Social Science Interface

Girod B, De Haan P (2009) GHG reduction potential of changes in consumption patterns and higher quality levels: Evidence from Swiss household consumption survey. Energ Policy 37(12):5650 5661

Girod B, De Haan P (2010) More or Better? A model for changes in household greenhouse gas emissions due to higher income. J Ind Ecol 14(1):31-49

Girod B, De Haan P, Scholz R (2011) Consumption-as-usual instead of ceteris paribus assumption for demand. Int J Life Cycle Assess 16(1):3-11

Goedkoop MJ (1999) Product service systems, ecological and economic basics, Ministry of Housing, Spatial Planning and the Environment, Communications Directorate

Goedkoop MJ, Te Riele H, Van Halen C, Rommens P (1998) Product service combinations. Proceedings of the 3rd International Conference on Ecobalance, Tsukuba, pp 25-27

Greening A, Greene DL, Difiglio C (2000) Energy efficiency and consumption-the rebound effect: a survey. Energ Policy 28(6-7): 389-401

Heijungs R, Huppes G, Guinée J (2009) A scientific framework for LCA. Deliverable (D15) of work package 2 (WP2) CALCAS project

Hertel T (1999) Global trade analysis: modeling and applications. Cambridge, University Press

Hertwich EG (2005) Consumption and the rebound effect: an industrial ecology perspective. J Ind Ecol 9(1-2):85-98

Hofstetter P, Madjar M (2003) Linking change in happiness, timeuse, sustainable consumption, and environmental impacts; an attempt to understand time-rebound effects. Final report to the Society for Non-Traditional Technology. Japan/BAO \& Consultrix, Zurich

Hofstetter P, Bare JC, Hammitt JK, Murphy PA, Rice GE (2002) Tools for comparative analysis of alternatives: competing or complementary perspectives? Risk Anal 22(5):833-851

Hofstetter P, Madjar M, Ozawa T (2006) Happiness and sustainable consumption: psychological and physical rebound effects at work in a tool for sustainable design. Int J Life Cycle Assess 11(1):105115

Huppes G, De Koning A, Suh S, Heijungs R, Van Oers L, Nielsen P, Guinée JB (2006) Environmental impacts of consumption in the European Union: high-resolution input-output tables with detailed environmental extensions. J Ind Ecol 10(3):129-146

Jalas M (2002) A time use perspective on the materials intensity of consumption. Ecol Econ 41(1):109-123

Khazzoom JD (1980) Economic implications of mandated efficiency in standards for household appliances. Energ J 1(4):21-40

Kondo Y, Takase K (2007) An integrated model for evaluating environmental impact of consumer's behavior: consumption technologies and the waste input-output model. Advances in Life Cycle Engineering for Sustainable Manufacturing Businesses, pp 413-416

Manne AS, Wene CO (1992) MARKAL-MACRO: a linked model for energy-economy analysis. Brookhaven National Lab, Upton

Murray CK (2013) What if consumers decided to all 'go green'? Environmental rebound effects from consumption decisions. Energ Policy 54:240-256

Ornetzeder M, Hertwich EG, Hubacek K, Korytarova K, Haas W (2008) The environmental effect of car-free housing: a case in Vienna. Ecol Econ 65(3):516-530

Parke T (1987) The social constructions of technological systems: new directions in the sociology and history of technology the MIT Press 
Polimeni JM, Mayumi K, Giampietro M, Alcott B (eds) (2008) The Jevons Paradox and the Myth of Resource Efficiency Improvements. Earthscan

Pothen F (2010) Industrial ecology in policy making: what is achievable and what is not?, Centre for European Economic Research (ZEW) Environmental and Resource Economics, Environmental Management Research

Rajagopal D, Hochman G, Zilberman D (2011) Indirect fuel use change (IFUC) and the lifecycle environmental impact of biofuel policies. Energ Policy 39(1):228-233

Ramos-Martin J (2003) Empiricism in ecological economics: a perspective from complex systems theory. Ecol Econ 46(3):387-398

Roth IF, Ambs LL (2004) Incorporating externalities into a full cost approach to electric power generation life-cycle costing. Energy 29(12-15):2125-2144

Sandén B, Karlstrom M (2007) Positive and negative feedback in consequential life-cycle assessment. J Clean Prod 15(15):1469-1481

Saunders HD (2000) A view from the macro side: rebound, backfire, and Khazzoom-Brookes. Energ Policy 28(6-7):439-449

Seebregts AJ, Goldstein GA, Smekens K (2002) Energy/environmental modeling with the MARKAL family of models, Springer, pp 75-82

Sorrell S (2007) The rebound effect: an assessment of the evidence for economy-wide energy savings from improved energy efficiency. Project Report, UK Energy Research Centre

Sorrell S (2009) Jevons Paradox revisited: the evidence for backfire from improved energy efficiency. Energ Policy 37(4):1456-1469

Spielmann M, De Haan P, Scholz RW (2008) Environmental rebound effects of high-speed transport technologies: a case study of climate change rebound effects of a future underground maglev train system. J Clean Prod 16(13):1388-1398

Suh S, Huppes G (2002) Missing inventory estimation tool using extended input-output analysis. Int J Life Cycle Assess 7(3):134-140

Takahashi KI, Tatemichi H, Tanaka T, Nishi S, Kunioka T (2004) Environmental impact of information and communication technologies including rebound effects. In: Electronics and the environment, 2004. Conference Record. 2004 I.E. International Symposium, pp 13-16

Takase K, Kondo Y, Washizu A (2005) An analysis of sustainable consumption by the waste input-output model. J Ind Ecol 9(1-2): 201-219

Takase K, Kondo Y, Washizu A (2006) An analysis of consumers behavior by the waste input-output model: environmental impact of income and time use. Int J Life Cycle Assess Jpn 2(1):48-55
Thiesen J, Christensen T, Kristensen T, Andersen T, Andersen R, Brunoe B, Gregersen T, Thrane M, Weidema B (2006) Rebound effects of price differences. Int $\mathrm{J}$ Life Cycle Assess 13(2):104-114

Thomas BA, Azevedo ISL (2013a) Estimating direct and indirect rebound effects for U.S. households with input-output analysis Part 1: Theoretical framework. Ecol Econ 86:199-210

Thomas BA, Azevedo ISL (2013b) Estimating direct and indirect rebound effects for U.S. households with input-output analysis. Part 2: Simulation. Ecol Econ 86:188-198

Tukker A, Goldbohm RA, De Koning A, Verheijden M, Kleijn R, Wolf O, Pérez-Domínguez I, Rueda-Cantuche JM (2011) Environmental impacts of changes to healthier diets in Europe. Ecol Econ 70(10): 1776-1788

Van den Bergh JCJM (2011) Energy conservation more effective with rebound policy. Environ Resour Econ 48(1):43-58

Weidema B (1993) Market aspects in product life cycle inventory methodology. J Clean Prod 1(3-4):161-166

Weidema B, Thrane M (2007) Comments on the development of harmonized method for Sustainability Assessment of Technologies (SAT). Sustainability Assessment of Technologies

Weidema BP, Wesnaes J, Hermansen J, Kristensen J, Halberg N (2008) Environmental improvement potentials of meat and dairy products. Office for Official Publications of the European Communities, Luxembourg

Whitefoot KS, Grimes-Casey HG, Girata CE, Morrow WR, Winebrake JJ, Keoleian GA, Skerlos SJ (2011) Consequential life cycle assessment with market-driven design. J Ind Ecol 15(5):726-742

Wood R, Hertwich E (2013) Economic modelling and indicators in life cycle sustainability assessment. Int J Life Cycle Assess 18:1710 1721

Ybema JR, Kram T (1997) MARKAL modelling and scenarios relating to availability of new energy technologies. Energy Research Foundation ECN, Netherlands

Zamagni P, Buttol PL, Porta R, Buonamici R, Masoni P, Guinée J, Heijungs R, Ekvall T, Bersani R, Bienkowska A, Pretato U (2008) Critical review of the current research needs and limitations related to ISO-LCA practice. Deliverable D7 of work package 5 of the CALCAS project

Zamagni A, Guinée J, Heijungs R, Masoni P, Raggi A (2012) Lights and shadows in consequential LCA. Int J Life Cycle Assess 17(7):904 918 